\title{
Effect of the mould pressure on tribological property of carbon/phenolic resin composites
}

\author{
Yue Cao ${ }^{1}$, Midan $\mathrm{Li}^{1} \mathrm{a}^{*}$, Han Liu ${ }^{1}$, Mengyi Cao ${ }^{1}$, Jiawei Wang ${ }^{1}$, Yue Wang ${ }^{1}$, \\ Yijia Deng ${ }^{1}$ \\ ${ }^{1}$ Beijing Institute of Graphic Communication, No. 1, Xinghua Street, Da Xing District, Beijing \\ 102600, PR China \\ aemail: Imdjerry@sina.com
}

Keywords: Composites; Carbon; Hardness; Friction Coefficient; Wear Rate

Abstract. The carbon/phenolic resin composites consist of phenolic resin, natural graphite and carbon fiber, were fabricated by hot compression moulding. The effects of the mould pressure on tribological property of carbon/phenolic resin composites were investigated. The results indicated that the hardness increased, the friction coefficient and wear rate decreased with increasing mould pressure from $20 \mathrm{Mpa}$ to $40 \mathrm{Mpa}$, further increasing mould pressure the hardness and the wear resistance of composites changed slightly. The hardness, friction coefficient and wear rate of composites at $40 \mathrm{Mpa}$ were 64, 0.18 and $1.94 \times 10^{-6} \mathrm{~mm}^{3} \mathrm{~N}^{-1} \mathrm{~m}^{-1}$, respectively. The high hardness and complete transfer film were conttributed to good wear resistance of composites fabricated at 40MPa.

\section{Introduction}

Carbon/polymer composites combine excellent mechanical and tribological properties. They have been applied as attractive materials in a wide variety of applications, such as automotive, bearings, aerospace materials and railway transport systems [1-3]. Recently, a series of researches on the effects of preparing method on the properties of the polymer composites were carried out in literatures [4, 5]. Kaynak [4] developed layered silicate filled phenolic resin composites by mixing and casting, the effects of several different production parameters on the structure and mechanical property were investigated. Verbeek [5] developed phlogopite/LLDPE composites by compression moulding and the effects of preparation variables on flexural and tensile properties were discussed. However, there is little reported work examining the friction and wear behaviors of carbon/polymer composites fabricated under different production parameters.

In this manuscript, the carbon/polymer composites consist of phenolic resin, natural graphite and carbon fiber, are fabricated by a simple and low-cost hot compression moulding. Meanwhile, the effects of the mould pressure on tribological property of carbon/phenolic resin composites were investigated experimentally. Some composites were analyzed by SEM technique in order to evaluate the morphological characteristics of the worn surfaces of composite.

\section{Experimental}

Materials. The matrix polymer used in this work is a liquid resol type phenolic resin, which is a mixture of $60 \mathrm{wt} \%$ phenolic resin and $40 \mathrm{wt} \%$ ethanol. The fillers contain natural graphite and carbon fiber. The natural graphite has a flake shape, an average particle size of about $4 \mu \mathrm{m}$, and herein acted as the solid lubricant. The carbon fiber is polyacrylonitrile based, unsized and of diameter $7.2 \mu \mathrm{m}$, nominal length $4 \mathrm{~mm}$ and was chosen as the reinforcement.

Sample preparation. The mixture of phenolic resin, graphite and carbon fiber was mixed in a mechanical mixer for $10 \mathrm{~min}$ at $3000 \mathrm{rpm}$ speed, and then spread in a metal mould. The mould was placed on flat plate sulfuration bed and heated to $180{ }^{\circ} \mathrm{C}$. A pressure of $20-50 \mathrm{MPa}$ was applied and held for $1.5 \mathrm{~h}$ to fabricate the composite. After the mould was cooled at room temperature, the sample was pulled off from the mould.

Characterization techniques. Tribological properties of composites were characterized using a block-on-ring tribometer under dry sliding condition. The samples have the form of cubic blocks of 
$10 \mathrm{~mm} \times 10 \mathrm{~mm} \times 10 \mathrm{~mm}$. The counter-face material was a hardened steel ring with the outer diameter of $45 \mathrm{~mm}$ and the thickness of $6 \mathrm{~mm}$. The normal load was $150 \mathrm{~N}$ and the rotating speed of the steel ring was $400 \mathrm{rpm}$. A Shore hardness tester (HS-19GDV) was used to measure the hardness of each sample using a $36.2 \mathrm{~g}$ diamond ball and dropping height was $19.0 \mathrm{~mm}$. The hardness test samples were $20 \mathrm{~mm} \times 20 \mathrm{~mm} \times 10 \mathrm{~mm}$ in size. Morphological observation was performed on a Hitachi S4800 field-emitting scanning electron microscope. Prior to morphological observation, the surfaces of composite samples were vacuum-coated with a thin gold layer to avoid charging.

\section{Results and discussion}

Effect of mould pressure on hardness of carbon/phenolic resin composite. To study the effect of mould pressure on the tribological property of material, four different pressure values, 20, 30, 40 and $50 \mathrm{MPa}$ were selected to prepare the composites. The dependence of hardness on mould pressure for carbon/phenolic resin composites is displayed in Fig. 1. It is seen that the hardness of composites increased from 45 to 64 with increasing mould pressure from $20 \mathrm{MPa}$ up to $40 \mathrm{MPa}$, showing significant enhance effect on hardness of composites. Thereafter, with further increasing mould pressure, the hardness of composites decreased slightly.

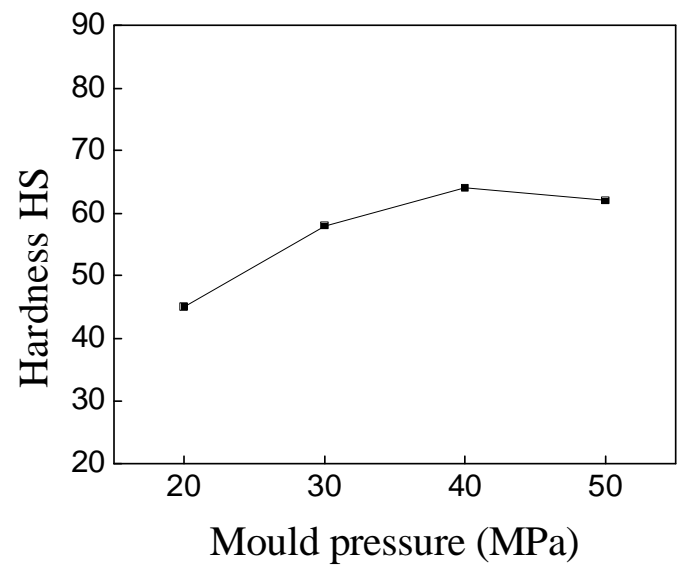

Fig. 1 Effect of mould pressure on the hardness of composites.

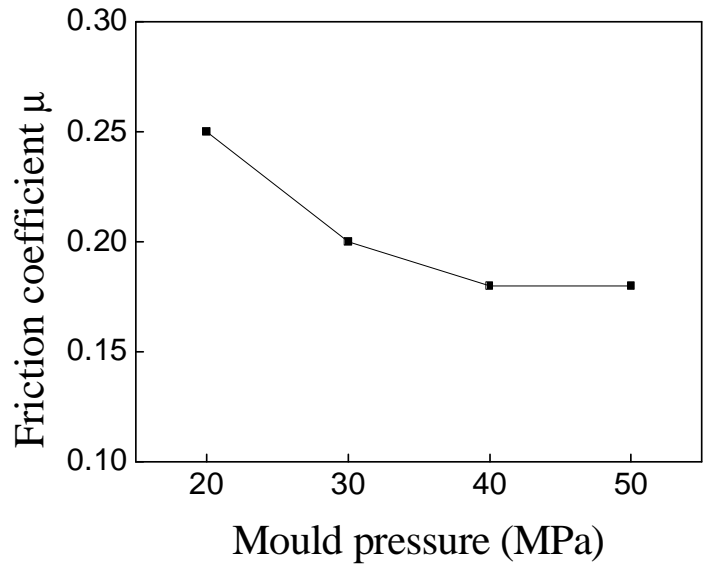

Fig. 2 Effect of mould pressure on the friction coefficient of composites.

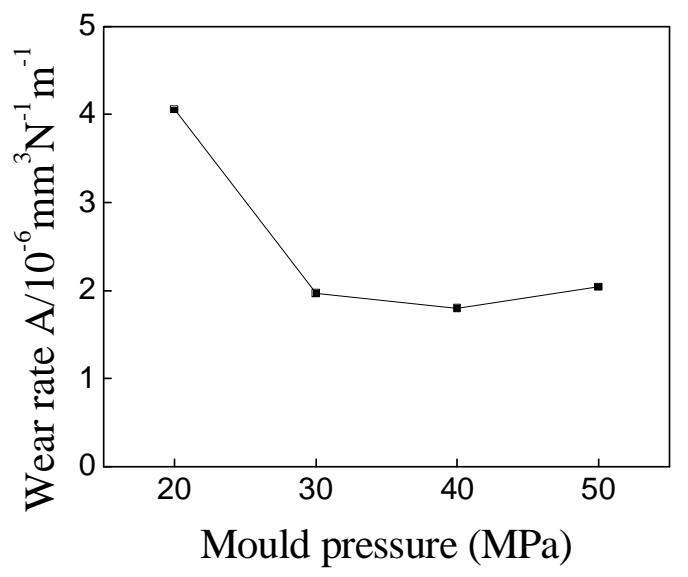

Fig. 3 Effect of mould pressure on the wear rate of composites.

To obtain high mechanical and tribological properties, a high filler loading concentration is needed as reported in literature [6]. However, a high viscosity of the mixture of resin and conductive fillers may contribute to the difficulties in processing and may cause formation of gaps inside the final composite [7]. Increasing the mould pressure during the compression moulding of 
the mixture caused the distances between the fillers to decrease, which eliminated gaps and increased the compaction.

Effect of mould pressure on friction coefficient and wear rate of carbon/phenolic resin composite. The tribological property of carbon/phenolic resin composites is largely influenced by mould pressure. As anticipated from Fig. 2 and Fig. 3, an increase in mould pressure was generally accompanied by decreases in friction coefficient and wear rate. Under $20 \mathrm{MPa}$ mould pressure, for instance, the friction coefficient of composite is about 0.25 and the wear rate is about $4.12 \times 10^{-6}$ $\mathrm{mm}^{3} \mathrm{~N}^{-1} \mathrm{~m}^{-1}$, whereas those of the composite under $40 \mathrm{MPa}$ are about 0.18 and $1.94 \times 10^{-6} \mathrm{~mm}^{3} \mathrm{~N}^{-1} \mathrm{~m}^{-1}$, respectively. Addition of $20 \mathrm{MPa}$ mould pressure therefore accounts for decreases more than $28 \%$ in friction coefficient and $53 \%$ in wear rate. However, when the mould pressure increased from 40 $\mathrm{MPa}$ to $50 \mathrm{MPa}$, the friction coefficient and wear rate of composite showed very little changes as shown in Fig. 2 and Fig. 3. It can be seen from Fig. 1-3 that the optimal mould pressure was 40 MPa.
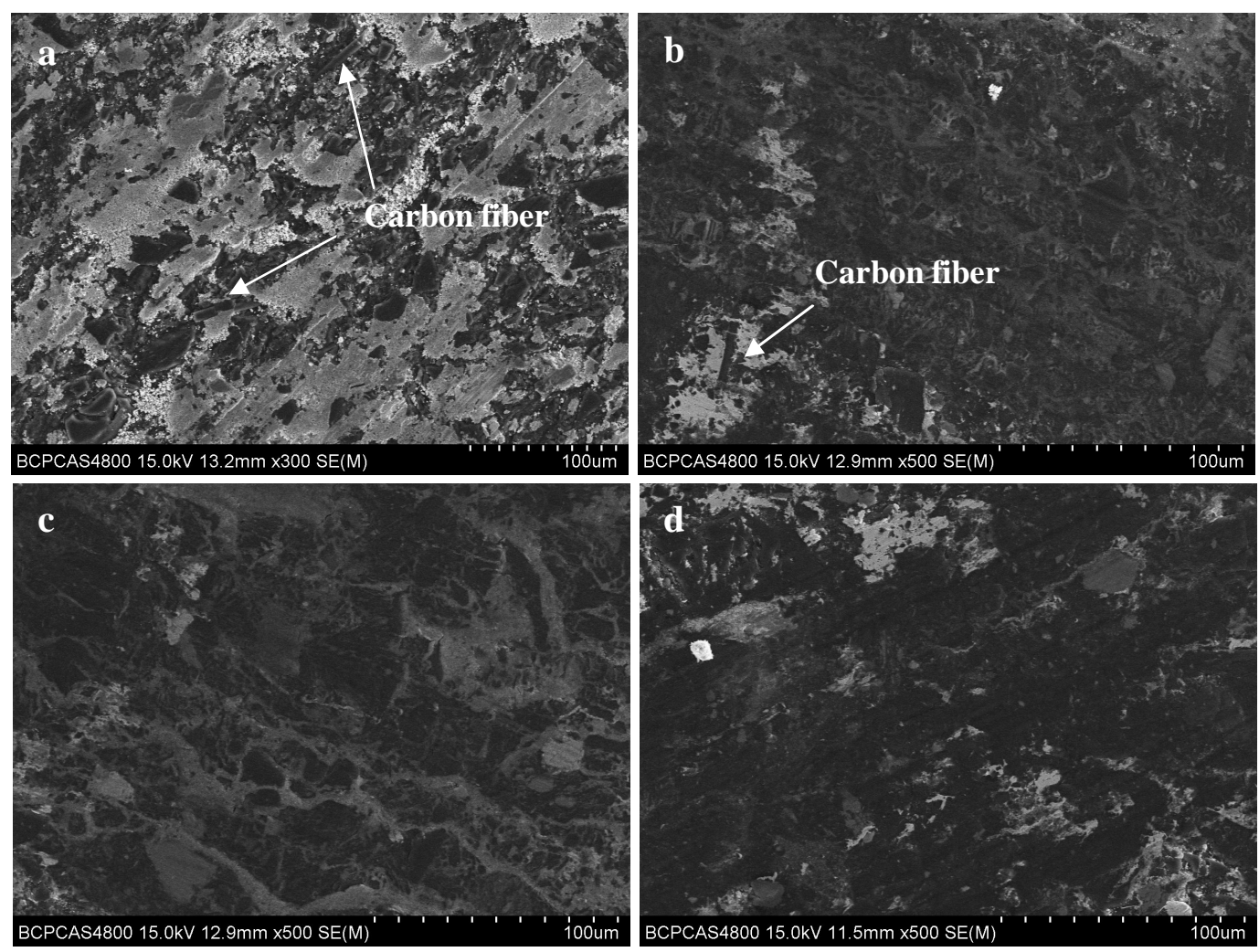

Fig. 4 SEM images of the worn surface of composites of pressure (a) $20 \mathrm{MPa}$, (b) $30 \mathrm{Mpa}$, (c) $40 \mathrm{Mpa}$ and (d) $50 \mathrm{Mpa}$.

Ho et al. [8] suggested that the friction coefficient is related to the formation of transfer film. For the composite under $20 \mathrm{MPa}$ mould pressure, the low bonding strength due to gaps forming leads to fiber particles easy to fracture or loosen from the matrix, bringing about lots of hard debris left on the worn surface, which disrupt transfer films. As described in Fig. 4(a), Carbon fiber particles are noticeable on the worn surface as shown by white arrows and the transfer film is discontinuous. The disruption of transfer film on the worn surface appeared to be responsible for the increased friction coefficient under $20 \mathrm{MPa}$ mould pressure. As the mould pressure increases, the bonding strength increases and the carbon fibers difficultly fall off from the matrix during the sliding process. This improves the formation of the complete transfer film (Fig. 4(b), 4(c) and (d)). So the friction coefficient is declined when the mould pressure increases over $30 \mathrm{Mpa}$ as shown in Fig. 2.

The wear resistance of the composites is closely related to the hardness, agreeing with Moustafa et al. [9] that the wear rate of a material was inversely proportional to the hardness of the wearing body. This can be further confirmed in this work that the composite fabricated at high mould pressure exhibits high hardness and low friction coefficient and wear rate, as shown in Fig. 1-3. In 
addition, the lessening of carbon fiber shedding at high mould pressure decreases the possibility of the severe abrasive wear. Morever, the presence of a complete transfer film prevents direct contact of the sample surface from friction pair. All of these factors are responsible for the good wear resistance of composites fabricated at high mould pressure.

\section{Conclusion}

Carbon/phenolic resin composites were prepared through simple and low-cost hot-compression molding. The effects of the mould pressure on tribological property of carbon/phenolic resin composites were investigated experimentally. With increasing mould pressure, the hardness of composites increased, friction coefficient and wear rate decreased. Under pressure of $40 \mathrm{MPa}$, the hardness, friction coefficient and wear rate of composites were $64,0.18$ and $1.94 \times 10^{-6} \mathrm{~mm}^{3} \mathrm{~N}^{-1} \mathrm{~m}^{-1}$ respectively. The high hardness and complete transfer film are conttributed to good wear resistance of composites fabricated at $40 \mathrm{MPa}$.

\section{Acknowledgements}

This work was financially supported by National Undergraduate Research Program (2015).

\section{References}

[1] I. Yasar, A. Canakci, F. Arslan, The effect of brush spring pressure on the wear behaviour of copper-graphite brushes with electrical current, Tribology International 40 (2007) 1381-1386.

[2] J.X. Wang, R.J. Zhang, J. Xu, C. Wu, P. Chen, Effect of the content of ball-milled expanded graphite on the bending and tribological properties of copper-graphite composites, Materials and Design 47 (2013) 667-671.

[3] X.C. Ma, G.Q. He, D.H. He, C.S. Chen, Z.F. Hu, Sliding wear behaviour of copper-graphite composite material for use in maglev transportation system, Wear 265 (2008) 1087-1092.

[4] C. Kaynak, C.C. Tasan, Effects of production parameters on the structure of resol type phenolic resin/layered silicate nanocomposites, European Polymer Journal 42 (2006) 1908-1921.

[5] C.J.R. Verbeek, Effect of preparation variables on the mechanical properties of compression-moulded phlogopite/LLDPE composites, Materials Letters 56 (2002) 226-231.

[6] S. Radhakrishnan, B.T.S. Ramanujam, A. Adhikari, High-temperature, polymer-graphite hybrid composites for bipolar plates: Effect of processing conditions on electrical properties, J. Power Sources 163 (2007) 702-707.

[7] H. Suherman, A.B. Sulong, J. Sahari, Effect of the compression molding parameters on the in-plane and through-plane conductivity of carbon nanotubes/graphite/epoxy nanocomposites as bipolar plate material for a polymer electrolyte membrane fuel cell, Ceramics International 39 (2013) 1277-1284.

[8] S.C. Ho, L.J.H. Chern, C.P. Ju, Effect of phenolic content on tribological behavior of carbonized copper-phenolic based friction material, Wear 258 (2005) 1764-1774.

[9] S.F. Moustafa, S.A. El-Badry, A.M. Sanad, Friction and wear of copper-graphite composites made with Cu-coated and uncoated graphite powders, Wear 253 (2002) 699-710. 